See Article page 212.

\section{Commentary: The arterial switch operation: Good for business}

\author{
Bahaaldin Alsoufi, MD
}

In the current issue of the Journal, Fricke and colleagues ${ }^{1}$ from Melbourne present their large single-institution experience with the arterial switch operation $(n=844$ from 1983 to 2015). They report long-term outcomes with a focus on survival and late reintervention. They found that at 25 years after surgery, freedom from reintervention was $77 \%$ and was worse for patients with ventricular septal defect compared with those with an intact ventricular septum. The most common reoperation was on pulmonary artery branches, followed by the neoaortic root and valve, then coronary arteries. They also found that there were no deaths beyond 14 months after surgery, and that survival was $95 \%$ at 25 years, with $98 \%$ of patients having normal ventricular function and the majority having good neoaortic valve function. However, they noted that among those who were 25 years or more postsurgery, nearly $15 \%$ had moderate or greater neoaortic valve insufficiency or had undergone valve replacement.

The study from Melbourne portraying long-term outcomes following the arterial switch operation emphasizes the excellent survival that has been described by other reports as well. ${ }^{2}$ This means that there will be an increasing adult population of patients who have undergone the arterial switch operation during infancy, and that number will soon exceed that of children with the same diagnosis. This is similar to adult patients with tetralogy of Fallot, who surpassed the number of children with the same diagnosis nearly 2 decades ago. Given the potential for development of late complications in this patient population, there will definitely be an increase in the number of patients being fol-

\footnotetext{
From the Department of Cardiovascular and Thoracic Surgery, University of Louisville School of Medicine, Louisville, Ky.

Disclosures: The author reported no conflicts of interest.

The Journal policy requires editors and reviewers to disclose conflicts of interest and to decline handling or reviewing manuscripts for which they may have a conflict of interest. The editors and reviewers of this article have no conflicts of interest.

Received for publication March 19, 2021; revisions received March 19, 2021; accepted for publication March 23, 2021; available ahead of print March 26, 2021 Address for reprints: Bahaaldin Alsoufi, MD, Department of Cardiovascular and Thoracic Surgery, University of Louisville School of Medicine, Norton Children's Hospital, 201 Abraham Flexner Way, Suite 1200, Louisville, KY 40202 (E-mail: balsoufi@hotmail.com).

J Thorac Cardiovasc Surg 2022;163:220-1

0022-5223/\$36.00

Copyright (c) 2021 by The American Association for Thoracic Surgery

https://doi.org/10.1016/j.jtcvs.2021.03.075
}

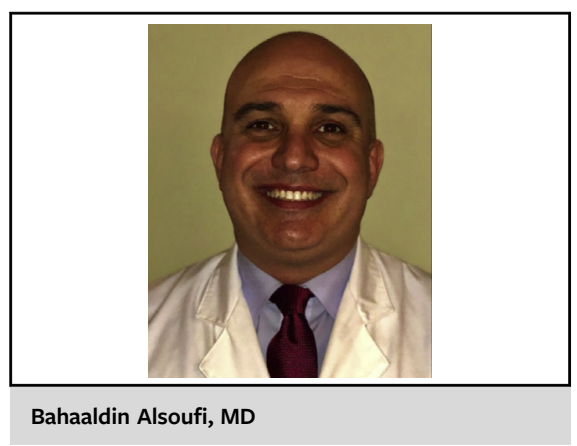

CENTRAL MESSAGE

Excellent survival and inherent

late complications after arterial

switch have created a growing

population of patients who

require follow-up and potential

intervention in adulthood.

lowed by the ever-growing adult congenital cardiology service. In patients with tetralogy of Fallot, understanding the long-term complications following surgery has led to innovations in the medical, percutaneous, and surgical management of these problems, in addition to technical modifications at time of initial repair to decrease the potential for development of these problems (eg, pulmonary valve preservation). Similarly, understanding the longterm complications following arterial switch operation has triggered some potential surgical modifications and late innovations to decrease the development of and to manage these various late problems.

Several surgical modifications have been developed to decrease the risk of late surgical complications. Pulmonary artery stenosis has long been identified as the most common cause for reintervention, and several technical changes (eg, extensive pulmonary artery branch mobilization, use of large patches to reconstruct the pulmonary sinuses, shortening of the ascending aorta) have successfully decreased its occurrence. ${ }^{3}$ Coronary artery obstruction, although rare, can be associated with major morbidity. Experience gained with the implantation of the challenging coronary patterns has decreased early mortality and potentially late obstruction risk. ${ }^{4}$ Dilatation of the neoaortic root and development of neoaortic regurgitation are emerging late problems with risk factors that include previous pulmonary artery banding, ventricular septal defect, and significant size mismatch (eg, Taussig-Bing anomaly and those with arch obstruction). Some surgeons proposed that certain repair techniques might 
be associated with preservation of the neoaortic root geometry and subsequently lower late complications (eg, implantation of the coronaries as buttons within circular sinus opening as opposed to trap door incision, reduction of the neoaortic root to match the smaller ascending aorta). Nonetheless, to date there is no evidence that these techniques are associated with decreased risk of development of neoaortic root dilatation or valve regurgitation. Short of early primary repair and avoidance of an initial pulmonary artery band, it seems that this neoaortic root and valve pathology are problems inherent to the use of the pulmonary valve and artery in the systemic circulation and that they will become the Achilles' heel affecting late outcomes following the arterial switch operation.

As for management of these late complications, the usual surgical techniques to tackle pulmonary artery stenosis and coronary artery obstruction have been applied in patients who developed these complications following an arterial switch operation. On the other hand, although neoaortic valve replacement with or without root replacement has been traditionally performed in patients with neoaortic valve and root pathology, innovative strategies, such as the switchback procedure (ie, Ross procedure after arterial switch, usually reserved for children with severe neoaortic valve regurgitation), and valve-sparing procedures (ie, neoaortic valve repair using various techniques, with or without valve-sparing root replacement) have been increasingly described with promising early results.
In summary, excellent outcomes following the arterial switch operation have led to a growing number of survivors who require continuous follow-up by pediatric and adult congenital cardiology services. Late complications are not infrequent and also have led to increased percutaneous and surgical reinterventions. Neoaortic valve and root complications are being increasingly reported in older patients, and these late complications are likely inherent to the nature of this surgery and the transfer of the pulmonary valve and artery into the systemic circulation. Innovative techniques to treat these pathologies while preserving the neoaortic valve have been used with encouraging early results.

\section{References}

1. Fricke TA, Buratto E, Weintraub RG, Bullock A, Wheaton G, Grigg L, et al Long-term outcomes of the arterial switch operation. J Thorac Cardiovasc Surg. 2022; 163:212-9.

2. Losay J, Touchot A, Serraf A, Litvinova A, Lambert V, Piot JD, et al. Late outcome after arterial switch operation for transposition of the great arteries. Circulation. 2001;104(12 Suppl 1):I121-6.

3. Alsoufi B, Cai S, Williams WG, Coles JG, Caldarone CA, Redington AM, et al. Improved results with single-stage total correction of Taussig-Bing anomaly. Eur J Cardiothorac Surg. 2008;33:244-50.

4. Ou P, Khraiche D, Celermajer DS, Agnoletti G, Sang KLQ, Thalabard JC, et al. Mechanisms of coronary complications after the arterial switch for transposition of the great arteries. J Thorac Cardiovasc Surg. 2013;145:1263-9.

5. Lo Rito M, Fittipaldi M, Haththotuwa R, Jones TJ, Khan N, Clift P, et al. Long term fate of the aortic valve after an arterial switch operation. J Thorac Cardiovasc Surg. 2015;149:1089-94.

6. Lange R, Cleuziou J, Hörer J, Holper K, Vogt M, Tassani-Prell P, et al. Risk factors for aortic insufficiency and aortic valve replacement after the arterial switch operation. Eur J Cardiothorac Surg. 2008;34:711-7. 